\title{
Construction of china sports capital market system
}

\author{
Bing Zhang ${ }^{1, a}$, Kunling Qin², Zhisheng Liu ${ }^{1}$, Yanni Liu ${ }^{1}$ and Hongliang Yang ${ }^{1}$ \\ 1 Institute of Physical Education, Huanggang Normal University, Huangzhou 438000, China \\ ${ }^{2}$ Yidu Gaobazhou Middle School, Yidu 443300, China
}

\begin{abstract}
The paper systematically analyzes and states China sports capital market system influence factors specific to China sports capital market system construction, and makes analysis and research on the system, it proceeds multi-objective decision analysis by dynamic integration of qualitative analysis and quantitative analysis through expert investigation method, mathematical statistics and analytic hierarchy process these methods, as well as carries out analyzes China sports capital market system various indicator influence factors' weights, obtains comparison matrix through comparing with paired factors, and finally concludes each indicator value of factor weight that affects China sports capital market system by arrangement and other methods as respectively funding needs cover $40.2 \%$ of overall proportion, technical requirements cover $30.2 \%$ of overall proportion, while talent needs cover $28.3 \%$ of overall proportion, the result provides theoretical preparation for researches on the relevant fields in future.
\end{abstract}

\section{Introduction}

Industrial investment as an innovation tool in financial circle in the 90 s of last century has been popular; it enriches capitalism market through standard operation, professional management and collective fund as well as others, and so doe's sports capital market from them that plays an important role and has become one of the richest industries.

Regarding sports capital aspect study, many people have made contributions, such as Lu Xiao-Mei during researches on sports industrial investment, she obtained China investment industrial necessity and feasibility through analyzing and comparing relating to world investment fund development mode, analyzing world sports capital market development and corresponding system and others internal connection, and combining with China actual conditions, and thus designed China sports industry investment fund theoretical frame; Zhang Han analyzed China sports industrial market financing strategic significance and development countermeasures in China sports industry investment market development, with the purpose of seeking a strategic pattern that could drive China sports industry capital market development [1-4].

The paper just bases on above formers' researches, carries out further analyses and researches on China sports capital market development situations, implements deepening sports system reform presented by the Party Central Committee, encourages the spirits of developing sports through social force, provides theoretical supports for China sports capital market system construction, and of an important significance in improving China sports comprehensive strength.

\footnotetext{
a Corresponding author: tiyuxi@qq.com
}

\section{China sports capital market system evaluation system theoretical analysis}

Sports capital market is a capital operational mode that common constituted by finance, science and technology, innovation as well as sports, due to economic globalization lets sports capital market plays certain promotions roles in sports industrial development, it creates miracles for sports market again and again [5].

A system is composed of multiple elements, these elements determine system attributes, and so they become foundation of comprehensive evaluation theory. Therefore, comprehensive evaluation has become sports capital market system central contents in research concerning China sports capital market system, and it draws China sports capital market system indicator system flow chart as Figure 1 through combining with the paper researched contents.

It is worth noting that changes will occur to results of above evaluation system during running procedures as environment, subject and object become different, but the effect is not much, just pay attention to arrangement during input data processes can avoid such affect. Regarding China sports capital market analysis, due to each variable unit is not the same, it needs to implement nondimensionalization handling, from which there are various handling methods regarding nondimensionalization, one common used method is a method of relativity processing, the principle is firstly determining a standard indicator $x_{m}$, after that comparing the rest indicators $x_{i}$ with the standard indicator $x_{m}$, so that it can obtain 
implementation extent of every indicator, and corresponding formula is :

$\frac{x_{i}}{x_{m}} \times 100 \%=$ implementation extent of single indicator $(i=1,2, \cdots, n)$

The various indicators total evaluation system can be obtained after certain processing multiple factors, the method is called comprehensive evaluation method. Formers have presented many kinds of ways on the method, combing with the paper researched contents, the common used methods as weighted geometric mean method and arithmetic method by most scholars are chosen.

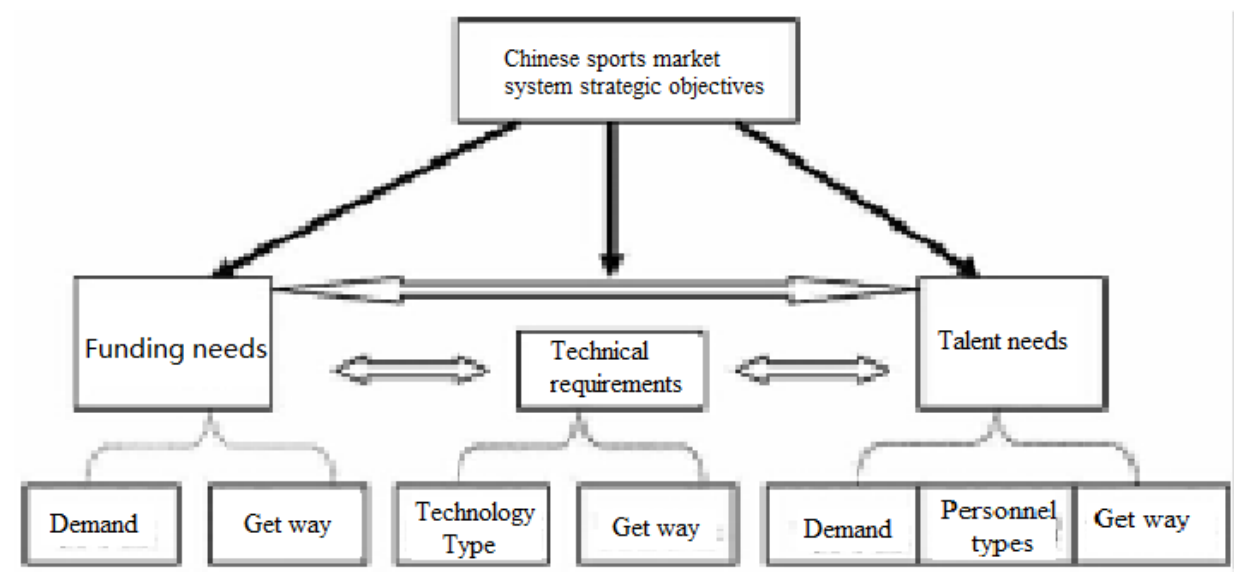

Figure 1. China's sports market system diagram.

\section{Analytical hierarchy process model}

AHP features are hierarchizing complicated problems, making clear about primary and secondary, possessing stronger logicality and hierarchical structure, the algorithm mainly is calculating indicators weights. It is applicable to comprehensive assessment system, is a powerful mathematical method that converts problems into quantitative research. Nowadays analytic hierarchy process has already widely used in each field to solve practical problems. China sports capital market system concerns multiple reference indicators, the decision problems is suitable to analytic hierarchy process [6].

\subsection{Construction of hierarchical structure}

At first it establishes an orderly, clear hierarchical structure for problems, firstly establishes three layers relationships, target layer, medium layer, scheme layer. Classified layers numbers are related to research objects complex extent and detailed extent. The paper bases on analytic hierarchy process; it quantizes China sports capital market system. Establish target layer, criterion layer, scheme layer relations. Target layer: China sports capital market system: Criterion layer: Scheme influence factors, $c_{1}$ is demand, $c_{2}$ is approach of achieving, $c_{3}$ is technological type, $c_{4}$ is talent type.

Scheme layer: $A_{1}$ is funding needs, $A_{2}$ is technical requirements, $A_{3}$ is talent needs.

It gets hierarchical structure as Figure 2 show.

\subsection{Hierarchical single arrangement and consistency test thereof}

Judgment matrix consistency indicator $C I$, and judgment matrix consistency ratio $C R$, their computational method is as following formula: $C I=\frac{\lambda_{\max }-n}{n-1}$.

Among them, $n$ represents judgment matrix order number that is the number of comparison factors. $C R=\frac{C I}{R I}$

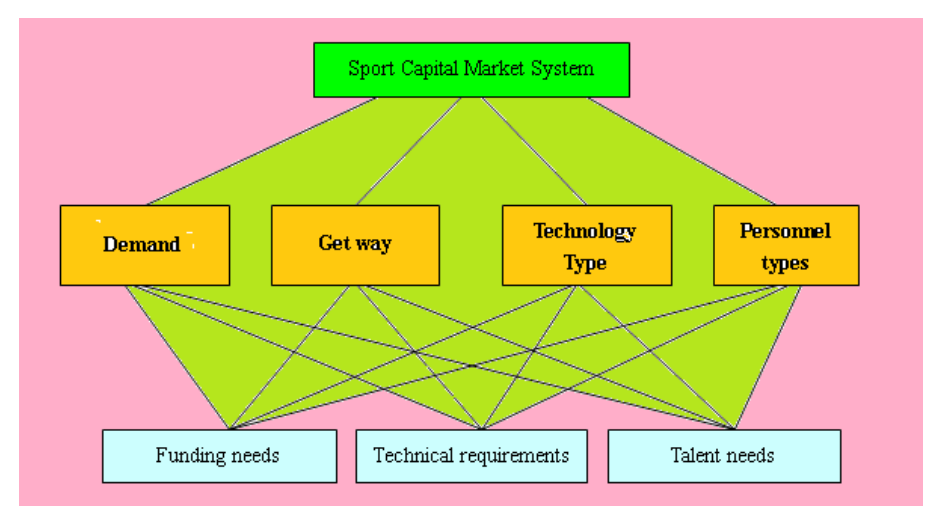

Figure 2. Hierarchy Figure. 


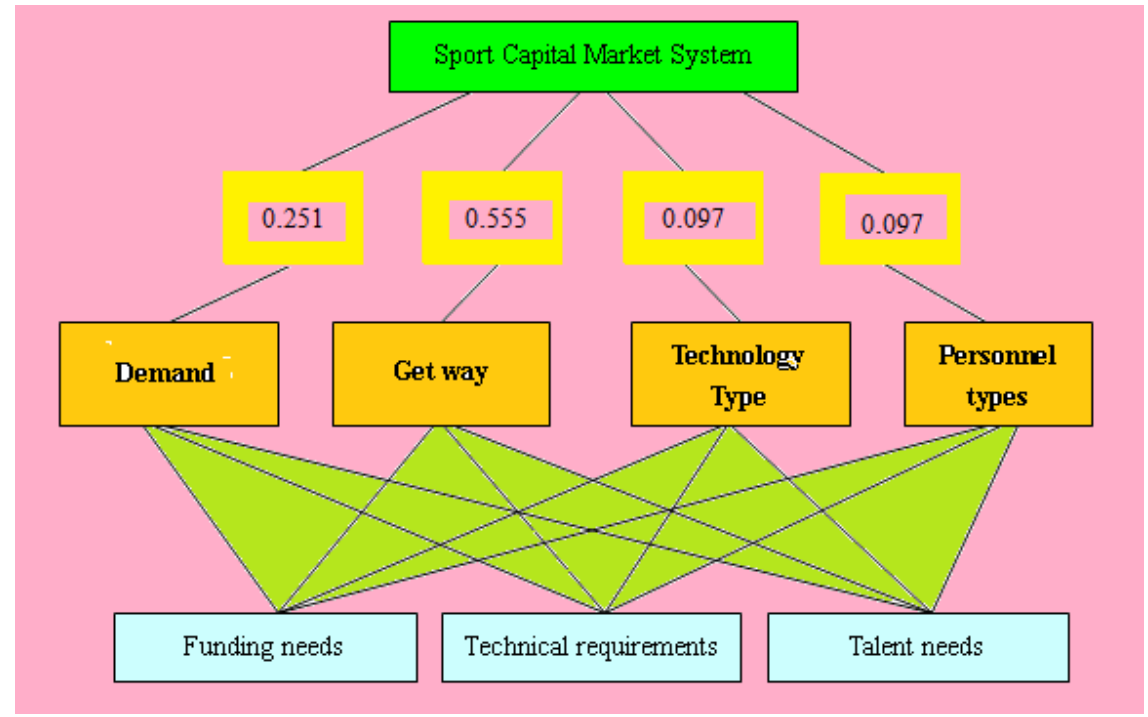

Figure 3. Weighted index system diagram.

\subsection{Hierarchical total arrangement and consistency test thereof}

Use consistency indicator to test and get judgment matrix $A, \lambda_{\max }^{(0)}=4.07, R I=0.9$

$$
C I=\frac{4.07-4}{4-1}=0.24 \quad C R=\frac{C I}{R I}=\frac{0.024}{0.90}=0.027<0.1
$$

It shows A inconsistency test is valid and moves within permissible range, it can use A feature vector to replace weight vector.

(2) Similarly carry out consistency test on judgment matrix $B_{1}, B_{2}, B_{3}, B_{4}$, and get weight vectors.

Utilize hierarchical chart drawing out calculation results that are from target layer to scheme layer, as Figure 3 shows.

Calculation structure is as following:

$$
\begin{aligned}
\omega^{(1)} & =\left(\omega_{1}^{(1)}, \omega_{2}^{(1)}, \omega_{3}^{(1)}, \omega_{3}^{(1)}\right) \\
& =\left\{\begin{array}{llll}
0.624 & 0.185 & 0.252 & 0.575 \\
0.234 & 0.240 & 0.089 & 0.286 \\
0.136 & 0.575 & 0.66 & 0.139
\end{array}\right\} \\
w & =w^{(1)} w^{(0)} \\
& =\left\{\begin{array}{llll}
0.262 & 0.585 & 0.664 & 0.185 \\
0.079 & 0.276 & 0.220 & 0.240 \\
0.66 & 0.149 & 0.156 & 0.575
\end{array}\right\}\left\{\begin{array}{l}
0.567 \\
0.056 \\
0.104 \\
0.273
\end{array}\right\} \\
& =\left\{\begin{array}{l}
0.426 \\
0.301 \\
0.284
\end{array}\right\}
\end{aligned}
$$

By above result we can get that during China sports market system construction, funding needs cover $40.2 \%$ of overall proportion, technical requirements cover $30.2 \%$ of overall proportion, while talent needs cover $28.3 \%$ of overall proportion.
The paper systematically analyzes and states China sports capital market system influence factors through China sports capital market system construction, and makes analysis and research specific to the system thereof, it proceeds multi-objective decision analysis by dynamic integration of qualitative analysis and quantitative analysis through combining with the method of analytic hierarchy process, as well as carries out analyzes China sports capital market system various indicator influence factors' weights, obtains comparison matrix through comparing with paired factors, and finally concludes each indicator value of factor weight that affects China sports capital market system by arrangement and other methods.

\section{Acknowledgment}

This research was supported by State general administration of sports philosophy and social sciences research project: based on "Internet + " the sport and tourism integration development path of research (project number: 2322SS16059).

\section{References}

1. F. Dong, X.Z. Wu, L. Zhang, Journal of Nanjing Institute of Physical Education. 26, 35-41 (2012).

2. L. Zhang, L.Y. Wang, X.J. Xu, C. Liu, Journal of Shanghai Physical Education Institute. 31, 38-43 (2007).

3. X.B. Mei, X. Liu, Journal of Chengdu Physical Education Institute. 38, 12-15 (2012).

4. X.P. Lin, China Sport Science. 20, 1-5 (2000).

5. F.Q. Li, Z.L. Liu, NFD 2010: International Conference on Network and Finance Development. 223-227 (2010).

6. L.C.M. Santos, Jr.M.M. Rollo, T.M. Costa, et al., Journal of Coastal Research. 685-689 (2016).

\section{Conclusion}

